Western University Scholarship@Western

Centre for the Study of International Economic Centre for the Study of International Economic

Relations Working Papers Relations

1982

\title{
Tariffs, Technology Transfer, and Welfare
}

Robert Feenstra

Ken Judd

Follow this and additional works at: https://ir.lib.uwo.ca/economicscsier_wp

Part of the Economics Commons

Citation of this paper:

Feenstra, Robert, Ken Judd. "Tariffs, Technology Transfer, and Welfare." Centre for the Study of International Economic Relations Working Papers, 8202C. London, ON: Department of Economics, University of Western Ontario (1982). 
ISSN $0228-4235$

ISBN $0-7714-0325-9$

CENTRE FOR THE STUDY OF INTERNATIONAL ECONOMIC RELATIONS

WORKING PAPER NO. $8202 \mathrm{C}$

TARIFFS, TECHNOLOGY TRANSFER, AND WELFARE

Robert Feenstra

and

Ken Judd

Department of Eronomics Library

FEB 91982

University of Western Ontario

This paper contains preliminary findings from research work still in progress and should not be quoted without prior approval of the author.

DEPARTMENT OF ECONOMICS

UNIVERSITY OF WESTERN ONTARIO

LONDON, CANADA

N6A 5C 2 


\title{
TARIFES, TECHNOLOGY TRANSFER, AND WELFARE *
}

\author{
by
}

Robert Feenstra

Columbia University

and

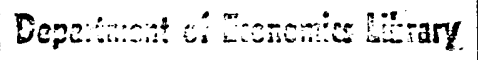

Ken Judd

Northwestern University

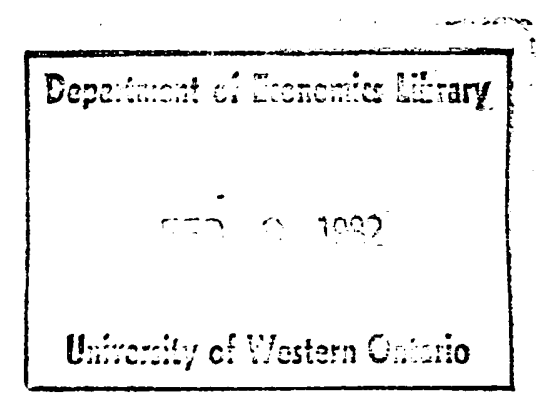

Revised, Dec. 1981

* The authors thank participants at International Trade workshops of the University of Chicago, NBER, and Columbia University for helpful comments. Special thanks to Rick Brecher, in particular, whose suggestions have been included in this draft. Financial support of the National Science Foundation is acknowledged. 


\section{Introduction}

It is widely recognized that the transfer of technology from developed to less-developed countries has an important impact on the pattern of trade and relative incomes across countries. A positive description of such technology transfer was presented some years ago by Vernon (1966), and the hypothesès of his celebrated "product cycle" have led to numerous empirical studies. But, unfortunately, it is difficult to obtain welfare-theoretic policy implications from the "product cycle" theory, since it is not explicitly based on the optimizing behavior of economic agents. In an important contribution, Krugman (1979b) develops an analytical model of the "product cycle," and obtains several welfare implications of changes in innovation and technology transfer. In his model the levels and rates of innovation and technology transfer are treated as parameters, and so the relationship between changes in actual commercial policy instruments (such as tariffs) and these parameters is an open question. Before policy recommendations can be made, this relationship must be determined. Other analyses of technology transfer are presented by Findlay (1978), McCulloch and Yellen (1976), Pugel (1980), and Rodriguez (1974).

In this paper we shall endogenously determine the level of technology transfer in an optimizing framework, and examine the effects of tariffs on technology transfer and welfare. Our basic model is similar to that of the recent theoretical literature on monopolistic competition and trade (see Dixit and Norman (1980), Helpman (1980), Lancaster (1980), and especially Krugman $(1979 a, c))$, which can be reviewed as follows. These models assume some fixed costs of production, resulting in economies of scale. Naturally, the fixed production cost or activity uses resources of the same country in which production occurs. With a monopolistically competitive market structure, 
the number or variety of goods produced is solved for in the zero-profit equilibrium. A change in trade opportunities due to liberalization or comercial policy will then affect world variety, which has a welfare impact additional to the usual welfare effect with a fixed number of goods. Our analysis differs from the above fixed cost models of monopolistic competition and trade in that the "fixed" production activity need not occur in the same country where production takes place. Specifically, we shall assume that the production of any good requires some initial research and development (R\&D) cost, and that this R\&D can be done in either country: the actual locational choice of R\&D activity will be determined by the optimizing behavior of firms. We shall adopt a very simple view of R\&D in which the costs to develop the technology to produce any good are a non-stochastic constant. Analytically, these R\&D costs are identical to the fixed costs of the usual monopolistic competition model, except that the R\&D costs are not country-specific. We shall identify R\&D activity done at home for production of goods abroad as technology transfer, and the extent of this technology transfer can be measured as the number of goods developed at home but produced abroad, multiplied by the R\&D cost per good.

Several limitations of our analysis can be noted at the outset. First, our model and equilibrium are static. That is, all goods are developed, produced, and consumed within the same (single) period. Equilibrium is obtained when a sufficiently large variety of goods are developed and marketed such that profits are zero. This static framework is used for convenience, but is still of considerable interest for analyzing R\&D and technology transfer: many of the effects we identify of tariffs on technology transfer, world variety, and welfare would undoubtedly carry over (in some form, at least) to a dynamic model. A dynamic analysis of product development under autarky 
is presented by Judd (1980); this material is sufficiently new and complex to deter application to a trade model at the present time.

Second, we shall assume that the tastes of each country are represented by identical, symmetric, CES utility functions. Symmetry of the utility function within any industry or group is needed to use free-entry monopolistic competition as the equilibrium concept. Then assuming a single group of commodities and a constant elasticity of substitution, it is known that under autarky the monopolistically competitive equilibrium is identical to the social optimum. ${ }^{1}$ That is, under autarky government intervention is not needed. Using a symmetric CES utility function is therefore both a limitation and a virtue: if tariffs are found to be desirable with trade, then this is not due to the possibility of correcting some distortion which exists under autarky, since the autarky equilibrium is socially optimal. That is, by using a CES utility function we are able to carefully separate the role of tariffs in correcting domestic distortions (which do not exist) and exploiting monopoly power in trade.

In the next section we shall determine the free trade equilibrium, and show how various combinations of relative country sizes and R\&D costs lead to different trade patterns. In section 3 we examine the effects of tariffs on technology transfer and welfare, considering in turn a uniform import tariff on goods, and export tariff on technology transfer; the effects of an export tariff on goods can be inferred fram these results. We consider only the effects of small changes in tariff rates around zero, that is, small movements away from the free trade equilibrium. In section 4 we rank the welfare impact of the various tariff instruments, again for small movements around the free trade equilibrium. Significantly, we find that the welfare gain per unit of revenue ralsed is maximized for the export tariff on technology 
transfer, followed by the import tariff on goods, with the export tariff on goods the poorest policy alternative. An intuitive explanation for this result is presented, based on the public good nature of technologies and also the elasticity of demand for technologies from firms. In section 5 we extend our analysis to include subsidization of R\&D for domestic production of goods as a policy instrument, and conclusions are given in section 6 . The derivations of mathematical results are gathered in the Appendix. 


\section{Trade Equilibrium and Patterns}

We assume that labor is the only factor of production, where the endowments of the home and foreign countries are given by $I$ and $L^{*}$. Labor in the two countries is equally efficient at producing goods, with one unit of labor required per unit of output, but have different efficiencies in RED activity: $k$ units of home labor are needed to develop the technology for any good, whereas $k^{*}$ units of foreign labor are required. Note that labor cannot migrate between the countries. Home and foreign wages are denoted by $w$ and $w^{*}$, where $\mu^{*} w^{*} / w$ is the relative foreign wage.

Letting $v$ and $v^{*}$ index home and foreign goods, respectively, we assume that domestic and foreign tastes are given by the identical, symmetric, CES utility functions

$$
u=\int_{0}^{v} x(v)^{c} d v+\int_{v}^{v+v^{*}} x\left(v^{*}\right)^{c} d v^{*}, \quad 0<c<1
$$

and

$$
U^{*}=\int_{0}^{v} x^{*}(v)^{c} d v+\int_{v}^{v+v^{*}} x^{*}\left(v^{*}\right)^{c} d v^{*}, \quad 0<c<1
$$

where $\mathrm{V}$ and $\mathrm{V}^{*}$ denote the variety (measure) of home and foreign goods produced, $x(v)$ and $x\left(v^{*}\right)$ are the quantities consumed at home of domestic and foreign goods, and $x^{*}(v)$ and $x^{*}\left(v^{*}\right)$ are the quantities consumed abroad of imported and local goods. ${ }^{2}$ The parameter $c$ of the utility function is related to $\sigma$, the elasticity of substitution, by $\sigma=1 /(1-c), \sigma>1$.

Several known properties of the CES utility function can be reviewed (see the Appendix). The elasticity of home, foreign, or world demand for any good is given by $\sigma=1 /(1-c)$. It follows that the profit-maximizing prices for goods produced at home and abroad are given by $w / c$ and $w * / c$, that is, constant proportional markups over variable cost. Thus, $\mu=w^{*} / w$ 
is the relative price of imported goods, or the inverse terms of trade, for the home country.

In writing the utility functions (1) we assume that no good is produced in both countries in the trade equilibrium. This assumption can be justified on the basis of positive fixed costs to transferring abroad a technology developed for use at home. That is, let $k\left(k^{*}\right)$ denote the amount of home (foreign) labor needed to develop a new technology for producing a good in either country, while $z\left(z^{*}\right)$ denotes the additional fixed cost needed to adapt an existing technology, used in one country, for production in the other. This structure amounts to a "putty-clay" assumption on R\&D, where ex ante the costs of developing a new technology for use in either country are equal, but ex post existing technologies cannot be costlessly transferred between countries. So long as the fixed costs $z$ and $z^{*}$ are positive and tariffs on trade are infinitesimally small, then no good will be produced in both countries with trade, which can be explained as follows.

Anticipating some of our equilibrium results, we shall find that in the free trade equilibrium wages are equalized across countries, so with small tariffs wages differ only slightly. The additional return available to any firm from transferring an existing technology and producing in both countries (for example, to "jump" a tariff barrier), clearly depends on the difference in wages, and when tariffs are infinitesimally small then so are the additional profits. In particular, the profits will be less than the fixed cost of transferring an additional technology, so this activity will not occur. Having established that a single firm will not a good in both countries, note that two (or more) firms will never produce the same good in a single or differing countries, since with symmetry of demand and costs the monopoly profits from developing a new product always exceed the duopoly profits from developing and marketing an existing product; thus, firms will 
specialize in different goods. Therefore, with infinitesimally mall tariffs and positive fixed costs to transferring an existing technology, no good will be produced in both countries with trade.

Firms in either country will choose to develop their product technologies in the country where R\&D costs wk or $w^{\star k} k^{*}$ are minimized. For the moment we shall assume that wk is less than $w^{\star} k^{*}$, so that all R\&D activity is done at home; after determining the trade equilibrium we shäl then establish the conditions under which this trade pattern holds. From this assumption, the extent of technology transfer is given by $V^{*} w k$, that is, the variety of goods developed at home but produced abroad, multiplied by the R\&D cost per good.

Using home labor as the numeraire (so $w=1$ ) and solving for commodity demands from utility maximization, the domestic and foreign profits from developing and marketing any good are given by

$$
\begin{aligned}
\pi & =\left(\frac{1}{c}-1\right)\left(x(v)+x^{*}(v)\right)-k \\
& =(1-c) \frac{\left(L+\mu L^{*}\right)}{\left(v+v^{*} \mu^{-d}\right)}-k, \quad d=\frac{c}{1-c}
\end{aligned}
$$

and

$$
\begin{aligned}
\pi^{*} & =\left(\frac{\mu}{c}-\mu\right)\left(x\left(v^{*}\right)+x^{*}\left(v^{*}\right)\right)-k \\
& =\mu^{-d}(I-c) \frac{\left(L+\mu^{*}\right)}{\left.V+v^{*} \mu^{-d}\right)}-k,
\end{aligned}
$$

where for convenience we have introduced the symbol $d=c /(1-c)=\sigma-1>0$. A more detailed derivation of these profit equations is given in the Appendix. Assuming free entry, an equilibrium condition of our model is that the variety of goods available must be sufficiently large such that profits are non-positive in each country. Assuming for the moment that goods are produced in both countries, from (2) and (3) the condition $\pi^{*}=0$ implies 


$$
\begin{aligned}
& \mu=w^{*} / w=I \\
& \left(v+v^{*}\right)=(I-c)\left(I+I^{*}\right) / k .
\end{aligned}
$$

The first condition states that wages are equalized across countries. The second condition determines the extent of world variety $V+V *$, and is shown as the line $\pi \pi^{*}$ in Figure 1, along which profits are zero.

Aside from zero profits, the remaining equilibrium condition is that trade must be balanced. Continuing to use home labor as the numeraire, the trade surplus of the home country is given by

$$
T=V x^{*}(v) / c+k V^{*}-V^{*} x\left(v^{*}\right) \mu / c
$$

where,

$$
\begin{aligned}
& V x^{*}(v) / c=\text { value of home exports of goods, } \\
& k v^{*}=v a l u e \text { of home exports of } R \& D, \text { or technology transfer, } \\
& V^{*} x\left(v^{*}\right) \mu / c=\text { value of home imports of goods. } \\
& \text { Using the condition } \mu=1 \text { from }(4), \text { and substituting for commodity de- }
\end{aligned}
$$
mands from utility maximization, the equilibrium condition $T=0$ can be written as

$$
\frac{V L *}{\left(V+V^{*}\right)}+k V^{*}=\frac{V^{*} L}{\left(V+V^{*}\right)}
$$

This trade balance equation is shown as the line of in Figure 1.

The free trade equilibrium is finally determined at the intersection of $\pi \pi^{*}$ and OT in Figure 1, that is, by the zero profit and trade balance conditions (4) and (6). Making use of the home country's full employment conaition

$$
\begin{aligned}
I & =k\left(V+V^{*}\right)+V\left(x(v)+x^{*}(v)\right) . \\
& =k\left(V+V^{*}\right)+V c\left(\frac{I+L^{*}}{V+V^{*}}\right), \text { when } \mu=1,
\end{aligned}
$$




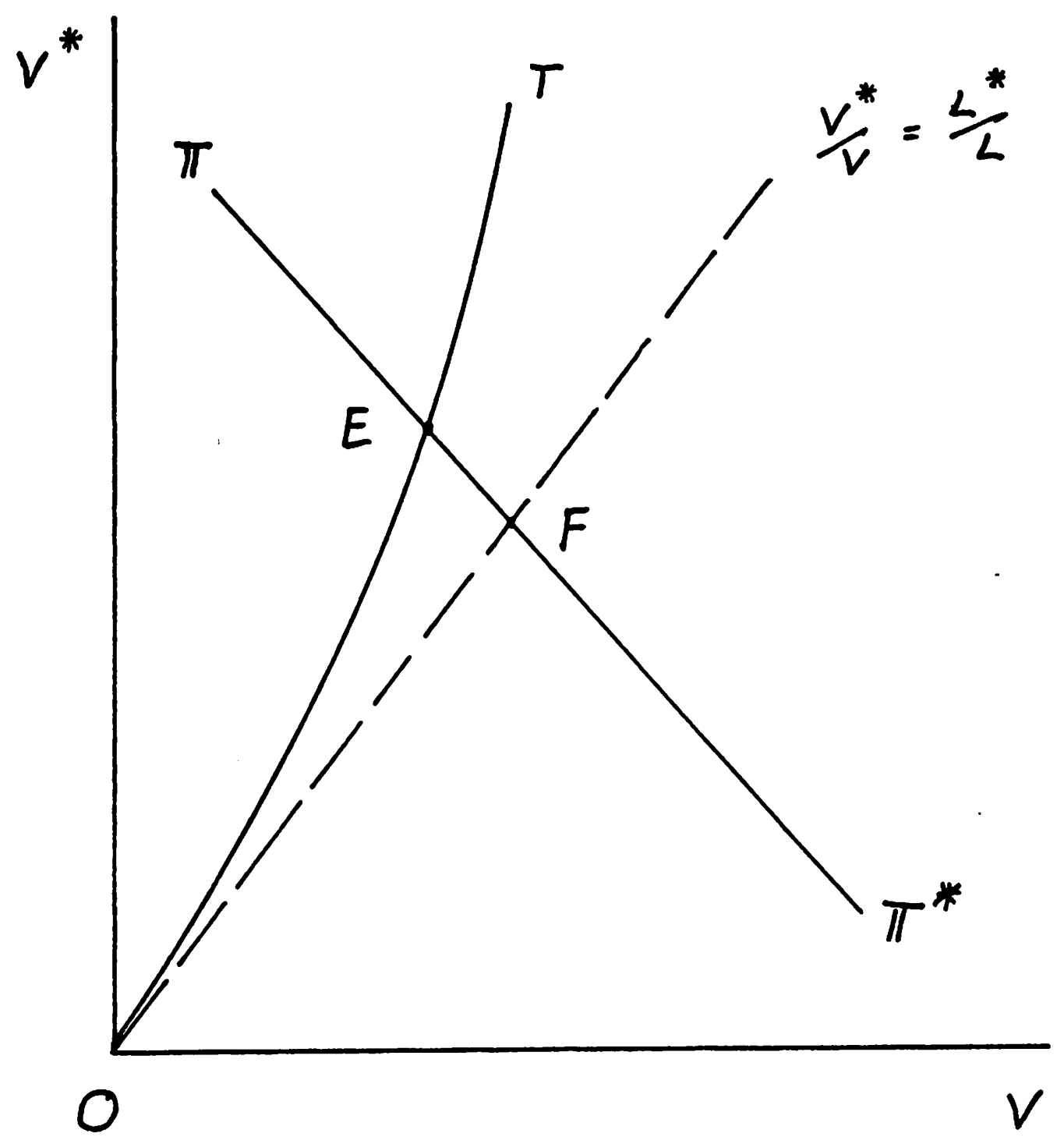

Figure 1 
conditions (4) and (6) can be used to solve for the equilibrium varieties in the two countries:

$$
\begin{aligned}
V^{*} & =\left(\frac{1-c}{c}\right) \frac{I^{*}}{k} \\
V & =(1-c) \frac{\left(L+L^{*}\right)}{k}-V^{*} \\
& =(1-c) \frac{L}{k}-\frac{(1-c)^{2}}{c} \frac{L^{*}}{k} .
\end{aligned}
$$

These equilibrium varieties are shown at the point $\mathrm{E}$ in Figure 1.

The dashed line in Figure 1 gives those combinations of country varieties such that the variety of goods produced in each country is proportional to its size (labor force). It can be seen that at the equilibrium $E$ the foreign country produces and exports a disproportionately large variety of goods; these exports are needed to purchase the imports of goods and technology from the home country. Because of its technology exports, the home country produces and exports a disproportionately small variety of goods, as compared with the position $F$. It can be shown that $F$ is the equilibrium of a fixed cost monopolistic competition trade model, in which $k=k^{*}$ and the fixed production cost or activity uses resources of the same country in which the goods are produced, that is, fixed costs are country-specific. ${ }^{5}$ At $F$ the country varieties are given by $V=(1-c) L / k$ and $V^{*}=(1-c) L * / k$.

So far we have assumed that R\&D activity takes place only in the home country, and that goods are produced in both. Since in this equilibrium wages are equalized across countries, the former assumption is satisfied if $k \leqq k^{*}$, so that all firms will choose to develop their technologies in the home country (or be indifferent). The condition under which goods are produced in both countries can be found by inspecting (7); the equilibrium variety produced at home is non-negative only if 


$$
\frac{L}{L^{*}} \geq\left(\frac{1-c}{c}\right)=\left(\frac{1}{\sigma-1}\right) \text {. }
$$

Thus, both of our initial assumptions are satisfied in the region (A) of Figure 2, leading to the trade pattern of technology transfer from home to abroad and "intra-industry" trade in goods.

If $L / L^{*}<1 /(\sigma-1)$, then the home country will specialize in R\&D activity, with goods produced only in the foreign country. Assuming for the moment that no technologies are developed abroad, full employment at home requires that $I=k V^{*}$, and so the equilibrium world variety is given by $V^{*}=L / k$, where $V=0$. The zero-profit condition for production of goods abroad becomes (see (3))

$$
\begin{aligned}
\pi^{*} & =(1-c)\left(\frac{I+\mu L^{*}}{V^{*}}\right)-k \\
& =(1-c)\left(\frac{I+\mu L^{*}}{L / K}\right)-k=0
\end{aligned}
$$

which implies

$$
\mu=\left(\frac{c}{1-c}\right) \frac{L}{L^{\star}}=(\sigma-1) \frac{L}{L^{\star}}
$$

Note that R\&D activity will take place only at home so long as wk\$w*k*, or $k / k^{*} \leq \mu$. Finally, it can be shown that home profits from the production of goods are non-positive so long as $\mu \leq l$.

In summary, the region in which the home country imports all goods and exports only technologies, while the foreign country exports all goods and imports only technologies, is shown by (B) in Figure 2. Under this trade pattern, world variety is determined by $\mathrm{V}^{*}=\mathrm{L} / \mathrm{k}, \mathrm{V}=0$, independent of the foreign country's labor force. The relative foreign wage is given by (9b), and is a decreasing function of the relative size of the foreign country. This may be contrasted with region (A), in which goods are produced in both countries and wages are equalized. 


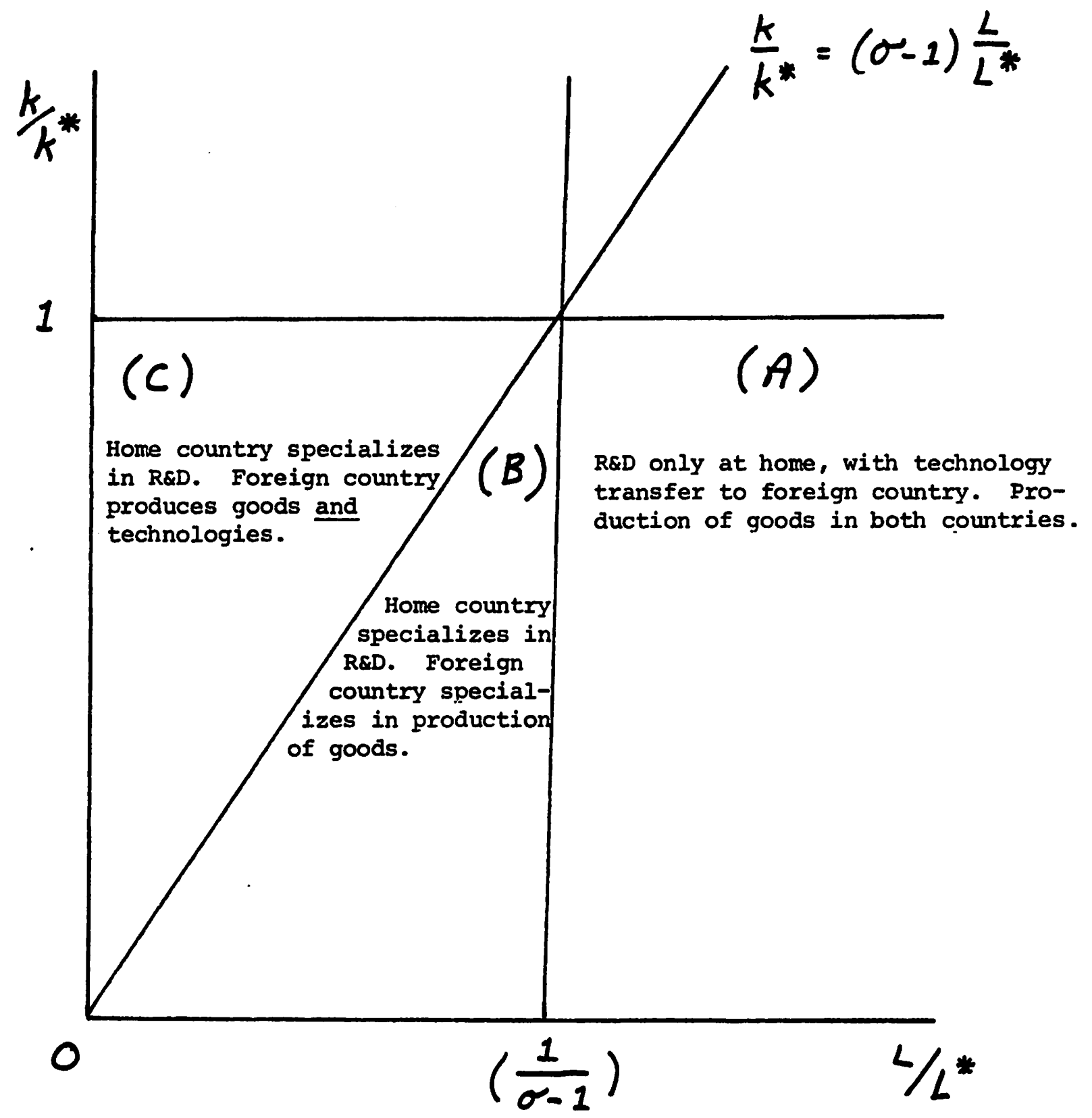

Figure 2 
Lastly, if the home country is small relative to the foreign labor force, domestic R\&D activity may be unable to support all the desired varieties produced abroad. This occurs in region (C) of Figure 2, where the home country specializes in R\&D activity but the foreign country produces goods and technologies. Since technologies are developed in both countries we must have $w k^{*} w^{*} k^{*}$ or $\mu=k / k^{*}$. Then from the zero-profit condition for production of goods abroad we have (see (3))

$$
\pi^{*}=(I-c)\left(\frac{L+I^{*} k / k^{*}}{V^{*}}\right)-k=0
$$

which implies

$$
V^{*}=(1-c)\left(\frac{L}{k}+\frac{L *}{k^{*}}\right) \text {. }
$$

The condition that home profits from production of goods be non-positive is again satisfied if $\mu \leq 1$. Thus, in region $(C)$ the relative foreign wage $\mu=k / k$ * is independent of country sizes, while world variety given in (10b) depends on the labor force of both countries.

This completes our description of the various trade equilibria and patterns. If $k>k^{*}$ in Figure 2 then we just reverse the roles of the domestic and foreign countries, and consider technology transfer from abroad to home. In the following section we examine the impact of tariffs on variety, the relative wage, and welfare under the various trade patterns, focusing our attention on region (A) where R\&D activity occurs only at home with goods produced in both countries. 


\section{Effects of Tariffs}

When the home country specializes in the R\&D activity, as in regions (B) and (C) of Figure 2, the effect of a uniform import tariff on goods or export tariff on technologies can be easily analysed. So long as these tariffs do not change the pattern of specialization, then they will have no real effects, leaving home and foreign utility and technology transfer $\mathrm{kV}^{*}$ unchanged. These result is most easily seen for the import tariff: since no goods are produced at home the tariff is equivalent to a lump sum tax on consumption, with the revenue returned, which has no equilibrium effects. A tariff on technologies can be analysed similiarly. 6

Turning to region (A), where goods are produced in both countries but R\&D occurs only at home, we shall examine the general equilibrium effects of a uniform import tariff on goods - denoted by $t$ - and export tariff on technology transfer - denoted by $\tau$. Due to the complexity of this comparative statics exercise (see the Appendix), we shall examine only small changes in the tariff rates around zero, that is, small movements away from the free trade equilibrium. Note that a uniform export tariff on goods and technologies has equivalent real effects to an equal value of the import tariff on goods; this is the Lerner Symmetry theorem applied to our model. Therefore, the effects of an export tariff applied to goods on domestic and foreign variety, and the terms of trade, can be readily inferred from the comparative statics results presented below. 7

\subsection{Import Tariff on Goods}

Evaluated at $t=0$, the effect of a uniform import tariff is

$$
\begin{aligned}
\frac{d V}{d t} & =\left(\frac{I-c}{c}\right) \frac{L V^{*}}{L+L^{*}}>0, \\
\frac{d V^{*}}{d t} & =\frac{-L V^{*}}{c\left(L+L^{*}\right)}<0, \\
\frac{d \mu}{d t} & =\frac{-I}{c\left(I+L^{*}\right)}<0,
\end{aligned}
$$


Thus, domestic variety rises, foreign variety and technology transfer $\mathrm{kV}^{*}$ fall, and the foreign wage is reduced. These results may be understood by noting that the import tariff shifts home demand towards domestic goods, thereby raising domestic profits and equilibrium variety, lowering foreign profits and equilibrium variety, and increasing the relative demand for, and wage of, labor at home. It can also be seen that world variety $\left(V+v^{*}\right)$ is reduced:

$$
\frac{d V}{d t}+\frac{d V^{\star}}{d t}=\frac{-I V^{*}}{L+I^{*}}<0
$$

With the import tariff the domestic relative price of imports is $\mu(1+t)$. While we expect this price to rise, according to the Metzler effect it is possible for the foreign terms of trade $\mu$ to decrease enough due to the tariff so that $\mu(1+t)$ actually falls. Evaluated at $t=0$, from (11) we have

$$
\frac{d}{d t}(\mu(I+t))=1-\frac{I}{c\left(L+L^{\star}\right)},
$$

so that $\mu(I+t)$ falls if $L /\left(L^{+} L^{*}\right)>c$. In order for the trade equilibrium to occur in region (A) of Figure 2, as assumed, condition (8) must be satisfied, which can be rewritten as

$$
\begin{aligned}
\frac{L}{L+L^{\star}} & >(1-c) \\
& >c \text { if } c<1 / 2 .
\end{aligned}
$$

Thus, if $c<1 / 2$ or equivalently $\sigma<2$, a Metzler effect occurs, with the domestic relative price of imports falling due to the tariff; note that this condition is sufficient but not necessary. The elasticity of substitution and demand $\sigma=1 /(1-c)$ applies to both domestic and foreign tastes, so $\sigma<2$ corresponds to relatively inelastic foreign demand, bearing some resemblance to the Metzler condition in standard two-good competitive trade models.

Using (11), the change in utility due to the import tariff can be written as 


$$
\begin{aligned}
\frac{l}{U} \frac{d U}{d t} & =\left(\frac{c}{V+V^{\star}}\right)\left\{V^{\star}-\left(1-\frac{L}{c\left(L+L^{*}\right)}\right) V^{*}-\left(\frac{1-c}{c}\right) \frac{V^{*} L}{L^{*} L^{\star}}\right\} \\
& =\left(\frac{1}{V+V^{\star}}\right) \frac{c L V^{\star}}{L+L^{\star}}>0 .
\end{aligned}
$$

The first term in the decomposition (12) refers to the effect of redistributed tariff revenue on utility, while the second and third terms are the effects of the change in the domestic relative price of imports $\mu(1+t)$ and world variety $\left(V+V^{*}\right)$, respectively. The fall in world variety has a negative impact on utility, but nevertheless the tariff is welfare-improving. It is interesting to note that if we ignore the first and third terms in (12), i.e., disregard the change in tariff revenue and world variety, then utility rises with the tariff if and only if there is a Metzler effect; this result can also be derived in standard two-good competitive trade models. However, continuing to ignore the redistribution of tariff revenue but including the decrease in world variety, utility will necessarily fall with the tariff, since

$$
-\left(I-\frac{I}{c\left(L+L^{*}\right)}\right) V^{*}-\left(\frac{I-c}{c}\right) \frac{V^{*} L}{L+L^{*}}=\frac{-L^{*} V^{*}}{L+I^{*}}<0 .
$$

\subsection{Export Tariff on Technology Transfer}

Evaluated at $\tau=0$, the effect of a tariff on the export of technologies is

$$
\begin{aligned}
& \frac{d V}{d \tau}=\left(\frac{1-c}{c}\right) V^{*}>0, \\
& \frac{d V^{*}}{d \tau}=\frac{-V^{*}}{c}<0, \\
& \frac{d \mu}{d \tau}=-\left(\frac{1-c}{c}\right)<0 .
\end{aligned}
$$

Not surprisingly, the tariff reduces the amount of technology transfer $\mathrm{kV}^{*}$. This reduction in variety tends to raise the demand for all goods, which increases domestic profits and the equilibrium variety $\mathrm{V}$ produced at home; the shift in the production of goods and labor demand towards the home country lowers the relative foreign wage $\mu$. The tariff on technology transfer also 
reduces world variety,

$$
\frac{d V}{d \tau}+\frac{d V^{*}}{d \tau}=-V^{*}<0
$$

The impact of these effects on home utility can be written as

$$
\begin{aligned}
\frac{I}{U} \frac{d U}{d \tau} & =\frac{(I-c)}{\left(V+V^{*}\right)}\left\{\frac{c\left(L+L^{*}\right) V^{*}}{I}+V^{*}-V^{*}\right\} \\
& =\frac{c k V^{*}}{I}>0, \text { using }(4) .
\end{aligned}
$$

As before, the first term in the decomposition (14) is the effect on utility of the redistributed tariff revenue, while the second and third terms are the effects of a change in the domestic relative price of imports $\mu$ and world variety $\left(V+V^{*}\right)$, respectively. The latter two effects cancel, and welfare is unambiguously improved due to the tariff on technology transfer.

As mentioned earlier, the effects of an export tariff on goods may be inferred from the above results using the Lerner Symetry theorem. Specifically, taking the difference between the comparative statics derivatives (11) and (13) yields the effects of the export tariff on domestic and foreign variety; taking the difference between (11') and (13) 'yields the effect on the domestic price of imports, ie. the relative foreign wage with an export tariff on goods. This dependence between the three tariff instruments will be used in the following section, where we rank the tariffs according to their impact on welfare.

Before proceeding to this, we should comment on the industry structure which has implicitly been assumed in the R\&D activity. There are two possibilities. First, the R\&D which accurs at home for production of goods abroad may be internally performed by home subsidiaries of foreign firms. ${ }^{8}$ This intra-firm 
transfer of knowledge would be difficult to observe and monitor, and in reality, may be less than fully reflected in the balance of payments. In this case a tariff on technology exports may not be a feasible policy instrument, and to affect the level of technology transfer the home country may have to use less direct policy measures, such as tariffs on the export or import of goods.

On the other hand, it is fully consistent in theory to assume that the R\&D industry is perfectly competitive and external to the goods industry. With free entry of firms into the goods industry, the demand curve for patented technologies is infinitely elastic at the level of monopoly profits earned, net of R\&D costs. The supply curve of patented technologies is horizontal at the marginal cost $k$ (or $k^{*}$ abroad), and equilibrium is established when the price of a patented technology is $k$, a result which we have already used. Also, since the total duopoly profits from two firms selling an identical product within the goods industry can be assumed less than the monopoly profits, it is in the interest of both buyers and sellers to ensure that all technologies are patented, i.e., can be sold to one and only one firm.

This sort of competitive sale of knowledge would be reflected in the services component of the current account, and should be accessible to policy intervention. The extent to which technology transfer can be controlled in reality depends on which of the two possible industry structures is predominant. When analyzing the effects of a tariff on technology exports in the following section, we shall be implicitly assuning a competitive R\&D activity, external to the goods industry. 


\section{Welfare Ranking of Tariffs}

The welfare effect of the tariffs analysed in the previous section can be directly compared by computing the welfare impact, per unit of revenue raised, for each of the policy instruments. This exercise can be performed with or without the redistribution of tariff revenues, where the government may choose to withhold the revenue in order to finance some other intervention, eg. subsidization of R\&D for domestic use, as analysed in the next section. It turns out that the ranking of the tariffs according to their welfare impact is independent of whether revenues are redistributed or not, so we shall make use of our results in the previous section and only report the case where revenues are distributed back to consumers. 9

To develop some intuition as to the comparative effects of the different tariff instruments, suppose we arbitrarily hold the terms of trade constant. Then for given varieties $\mathrm{V}$ and $\mathrm{V}^{*}$, an infinitesimal import tariff on goods will have no effect on home utility: for a small country the change in utility due to a tariff evaluated at free trade is zero, implying that the optimal tariff is zero.

Continuing to hold the terms of trade constant, let us compare this result with a small tariff on technologies. The change in home utility due to such a tariff is composed of two terms: the change in tariff revenue, and the change in utility due to the reduction in technology transfer and thus variety $V^{*} .10$ Evaluated at $\tau=0$ the change in tariff revenue. $\tau \mathrm{kV} *$ is just $\mathrm{kV}^{*}$. The tariff will reduce $\mathrm{V}^{*}$ according to the elasticity of demand for technologies from foreign producers, which is denoted $e_{v}^{*}>0$. Then the change in home utility, evaluated at free trade, is given by

$$
\frac{1}{\lambda} \frac{\partial U}{\partial \tau_{k}}=k V^{*}-\frac{1}{\lambda} \frac{\partial U}{\partial V^{*} / N^{*}} e_{v}^{*}=k V^{*}\left(1-\frac{1}{\lambda k} \frac{\partial U}{\partial V^{*}} e_{v}^{*}\right),
$$


where $\lambda$ is the marginal utility of incane.

To determine the sign of this expression, first consider the foreign demand for technologies. In the presence of the tariff $\tau$ on technology transfer, the profits of a foreign fim are given by

$$
\pi^{*}=\left(\frac{\mu}{c}-\mu\right)\left(x\left(v^{*}\right)+x^{*}\left(v^{*}\right)\right)-k(1+\tau)
$$

Since no R\&D is done in the foreign country, the output of any firm is just $L * N *$, and so

$$
\pi *=\mu\left(\frac{1-c}{C}\right) \frac{L^{*}}{V^{*}}-k(1+\tau)
$$

Then $\pi *=0$ implies

$$
\frac{(1+\eta)}{\mu} k V^{*}=\left(\frac{1-c}{c}\right) L^{*}
$$

The left hand side is the value of technologies transferred abroad, while the right hand side are total gross foreign profits (ie. before deducting R\&D costs). In a zero-profit equilibrium these are equal, and since the latter are proportional to the foreign labor force and therefore fixed, the elasticity of foreign demand for technologies $e_{v}^{*}$ is unity. Then from (15), the qualitative effect of the tariff on home utility depends on whether $\left(\partial u / \partial v^{*}\right)(1 / \lambda k)$ is greater or less than one.

For any good purchased by consumers, the marginal utility of consumption just equals its price times the marginal utility of income. Since $k$ is the price of technologies (evaluated at $\tau=0$ and with home wages as the numeraire), $\left(\partial v / \partial v^{*}\right)\left(1 / \lambda_{k}\right)$ can differ from unity only due to the special nature of technologies: while $V^{*}$ enters the consumers' utility function, it is not directly purchased, and so the marginal value to consumers need not equal 
its price to firms or resource cost. Notice that if $\left(\partial J^{\prime} / \partial^{*}\right)\left(1 / \lambda^{k}\right)$ did happen to equal one, as with conventional products, then from (15) a small tariff on technology transfer would have no effect on home welfare, as with a tariff on goods.

In fact, in equilibrium $\left(\not J / \partial^{*}\right)\left(1 / \lambda^{k}\right)$ is less than unity, implying that a small tariff on technology transfer raises hame utility, even when the terms of trade are held constant. This result may be obtained as follows. Recall from section 1 that the autarky monopolistically competitive equilibrium leads to the socially optimal level of variety. This means that with free trade the varieties $V^{*}$ and $V$ maximize world variety, defined as the sum the inverse of

of each country's welfare weighted by $\wedge^{i t s}$ marginal utility of income. Thus, with free trade

$$
\frac{\partial\left(U / \lambda+U^{*} / \lambda^{*}\right)}{\partial V^{*}}=k \text {, }
$$

le., the marginal value of a new foreign technology equals its marginal cost. From (16) we see that $\mathrm{J} / \mathrm{J}^{*}<\lambda^{k}$, so that (15) must be positive. Note that (16) reflects the public good nature of technologies, ie. the number or variety of products available is identical for all consumers in both countries, where the monopolistically competitive equilibrium leads to the socially optimal or Lindahl allocation of this "public good". Together with the result that $\mathrm{e}_{\mathrm{v}}^{*}$ is unity, this implies that the loss in utility due to reduced variety is less than the gain from tariff revenue. More generally, so long as the foreign elasticity of demand for technologies were inelastic, we would find from (15) that a small tariff on technologies would be welfare improving.

Holding the terms of trade constant, we have thus shown that a small tariff on technology transfer has a greater impact on home utility than a 
small tariff on goods. Of course, in our two country model tariffs will cause the terms of trade to change, and this effect can be compared per unit of revenue ralsed by the tariffs. For the tariff on technologies, the change In revenues $R_{\tau}=\tau \mathrm{kV}^{*}$ evaluated at. $\tau=0$ is $\mathrm{kV*}$, so dividing this into (13) we obtain the change in the inverse terms of trade per unit of revenue raised:

$$
\left.\frac{d \mu}{d R_{\tau}}=-\frac{1-c}{c}\right) \frac{1}{k V^{\star}}
$$

Considering the import tariff on goods, revenue is $R_{t}=t x\left(V^{*}\right) V^{*} / C$, and evaluated at $t=0, \partial R_{t} / \partial t=L V^{*} /\left(V+V^{*}\right) .^{11}$ Dividing this into (II) we obtain the terms of trade effect per unit of revenue raised for the import tariff:

$$
\frac{d \mu}{d R_{t}}=\frac{-I}{c\left(I+L^{*}\right)} \frac{\left(V+V^{*}\right)}{L V^{*}}=-\frac{I-c}{\left(\frac{1-}{c}\right)} \frac{1}{k V^{*}}
$$

since $k=(1-c)\left(L+L^{*}\right) /\left(V+V^{*}\right)$, from (4). Comparing $(17 a)$ and $(17 b)$ we see that per unit of revenue raised the tariffs on technologies and goods have identical effects on the terms of trade. Combined with our earlier result in (15), this suggests that allowing the terms of trade and variety to change in general equilibrium, a small tariff on technologies may be superior to a small tariff on goods, as we shall now examine.

For the import tariff on goods, we can divide the general equilibrium impact on utility (12) by the marginal revenue effect $\partial R_{t} / \partial t=L V^{*} /\left(V+V^{*}\right)$, and simplify to obtain

$$
\begin{aligned}
\frac{1}{\lambda} \frac{d U}{d R_{t}} & =1-\left(1-\frac{L}{c\left(I+I^{\star}\right)}\right)-\left(\frac{1-c}{c}\right) \frac{I}{I+I^{*}} \\
& =\frac{L}{I+I^{*}}<1,
\end{aligned}
$$


where $\lambda$ is the marginal utility of income. Similiarly, for the tariff on technology transfer we divide (14) by the marginal revenue effect $\mathrm{kV}^{\star}$ and simplify to obtain

$$
\frac{1}{\lambda} \frac{d U}{d R}=1+\frac{L}{C\left(I+L^{*}\right)}-\frac{L}{c\left(I+I^{*}\right)}=1 .
$$

As usual, the first terms in (18) and (19) are the effect of redistributed tariff revenue on utility, the second term reflects the change in the domestic relative price of imports, while the third term is the effect of the change in world variety. As noted in the previous section, for the import tariff the fall in utility due to reduced world variety always exceeds the rise (if any) due to a Metzler effect, so the change in revenue per unit revenue (18) is less than unity. However, for the tariff on technologies the terms of trade and world variety effects just cancel, and so utility rises by more than for the tariff on goods.

We can readily extend our analysis to include an export tariff on goods, since as noted earlier, a combined export tariff on goods and technologies is equivalent to an equal value of the import tariff on goods. Measuring the Impact on utility per unit of revenue raised, this means that a weighted average of the utility change for the export tariffs on goods and technologies equals the utility change for the import tariff on goods, where the weights are the proportions of goods and technologies in total exports. Combined with our result above, we therefore obtain a unique welfare ranking of the three pollcy instruments, for small movements away from the free trade equilibrium: the welfare gain per unit of revenue raised is maximized for the export tariff on technology transfer, followed by the import tariff on goods, with the export tariff on goods the poorest policy alternative. 


\section{Subsidization of R\&D for Domestic Use}

A policy instrument which we have not yet considered is the subsidization of R\&D done to produce goods domestically. As we now show, this policy is welfare-improving. Recalling that with CES utility functions the autarky equilibrium is also the social optimum, it seems likely that the subsidization of R\&D for domestic use together with tariffs on trade complete the list of desirable policy interventions.

Subsidizing the development of technologies for home use at the ad valorem rate $s$ requires that revenue of $s k v$ be raised from domestic consumers. Note that this policy is relevant only in region (A) of Figure 2. Domestic profits are given by

$$
\begin{aligned}
\pi & =\left(\frac{1}{c}-1\right)\left(x(v)+x^{\star}(v)\right)-k(1-s) \\
& =(1-c) \frac{\left(L-s k v+\mu L^{*}\right)}{\left(V+V \mu^{-d}\right)}-k(1-s), \quad d=\frac{c}{1-c} .
\end{aligned}
$$

which can be compared with (2). Domestic profits are an increasing function of the subsidy: evaluated at $s=0$,

$$
\begin{aligned}
\frac{d \pi}{d s} & =-(1-c) k\left(\frac{V}{V+V^{*}}\right)+k \\
& =(1-c) k\left(\frac{V^{*}}{V+V^{*}}\right)+c k>0 .
\end{aligned}
$$

The general equilibrium response to a change in the subsidy can be computed from the equilibrium conditions $\pi^{*}=0$ and $T=0$ (see the Appendix). Evaluated at $s=0$, we obtain

$$
\begin{aligned}
& \frac{d v}{d s}=c V+\frac{(1-c)^{2}}{c} V^{*}>0, \\
& \frac{d V^{*}}{d s}=-\left(\frac{1-c}{c}\right) V^{*}<0, \\
& \frac{d \mu}{d s}=-\left(\frac{1-c}{c}\right)<0 .
\end{aligned}
$$


As expected, subsidization of R\&D for domestic use increases the variety of goods produced at home and exported. The level of technology transfer $k V^{*}$ falls, while the shift in the production of goods and demand for labor towards the home country reduces the relative foreign wage. The effect of the subsidy on world variety $\left(v+v^{*}\right)$ is ambiguous as,

$$
\frac{d v}{d s}+\frac{d v *}{d s}=c v-(1-c) v^{*} \gtreqless 0
$$

Using (20) the change in utility due to the R\&D subsidy can be written as

$$
\frac{1}{U} \frac{d U}{d s}=\frac{(I-c)}{\left(V+V^{*}\right)}\left\{-c V \frac{\left(I+L^{*}\right)}{I}+\left(c V-(1-c) V^{*}\right)+V^{*}\right\}
$$

The first term in the decomposition (21) gives the negative impact on utility due to the revenue-cost of the subsidy. The second term is the effect of changing world variety, while the third term is the positive impact on utility of the decrease in the domestic relative price of imports $\mu$. It turns out that this positive terms of trade influence is large enough to dominate the first two effects; using (4) and (6) it can be shown that

$$
\frac{1}{U} \frac{d U}{d s}=c(1-c) \frac{k V^{*}}{L}>0
$$

Thus, starting at the free trade equilibrium, a small subsidy on the development of technologies for home use is welfare-improving. 


\section{Conclusions}

A significant conclusion of this paper is the efficacy of an export tariff on technology transfer. This result has been derived within a static framework where the level of technology transfer is endogenously determined by the optimizing behaviour of firms. As discussed at the end of section 3 , the feasibility of this policy intervention depends on the industry structure within the R\&D activity: if R\&D is internaliy performed by home subsidiaries of foreign firms then this technology transfer may be difficult to monitor and tax. ${ }^{12}$ on the other hand, if technologies are developed externally to the goods industry and marketed, then policy controls applied to the sale of technologies abroad would appear to be feasible.

It is useful to compare our result with that of Rodriguez (1975, section 1). Using a Ricardian model with a fixed number of goods (ie. two), and Ignoring the costs of R\&D, he finds that an optimal lump-sum royalty payment applied to the technology of one good is superior from the point of view of the transferring country to an optimal export tariff applied to the same good. This result, while similiar to ours in that it underscores the strength of tariffs (lump-sum royalties) applied to technologies, differs substantially from our principal conclusion in its derivation. Rodriguez obtains his result from the lump-sum nature of the royalty payment, as compared with royalties charged per unit of production or ad valorem tariffs on goods. Any monopolist can extract a greater surplus from the buyer by presenting only an "all or nothing" choice on a bundle of commodities (in this case, the entire quantity produced by the transferred technology), and the transferring country acts in this way when charging the optimal lump-sum royalty. The resulting situation is Pareto-optimal since product prices are identical across countries, consumers, and fims: the royalty payment has shifted the two countries along the world 
contract curve to the point where the country receiving the technology has the same level of welfare as in autarky, and the transferring country has secured the maximum gain. This type of reasoning does not apply to our analysis, since we have examined only small tariffs around the free trade equilibrium. As shown in section 4, our results depend on the extent of change in technology transfer when a tariff or royalty payment is applied, in addition to properties of the free trade quilibrium when the optimal variety is produced, while these considerations do not appear in Rodriguez' model. of course, it would be interesting to extend our analysis and examine optimal tariffs, in which case the reasoning which Rodriguez uses should apply, but these reasoning would be in addition to the effects we have separately identified.

Pursuing this comparison further, suppose we inquire as to the effects of small tariffs on technologies (ie.lump-sum royalties), or goods, in the Rodriquez model with a fixed number of goods and technologies. Let us assume that the royalty payments are government financed by lump-sum taxes in the receiving country, so that they have no direct effect on product prices. Then a tariff on technology transfer will affect the terms of trade simply by the transfer of royalty payments between the countries. If tastes are identical across countries, as we have assumed, then the terms of trade are not affected by this transfer, and the tariff on technologies will increase home welfare (real income) by the amount of revenue or royalty payments collected. In contrast, the welfare impact of a tariff on goods can be decomposed into the tariff revenue effect, and also the change in the domestic relative price of imports. Only if the latter is zero will welfare rise by the amount of revenues collected. Otherwise, welfare will rise by more or less than the redistributed revenue depending on whether the domestic relative price of imports falls or rises. In the absence of a Metzler effect, this price rises 
with the tariff on goods, and so per unit of revenue ralsed the tariff on technology transfer has a greater positive impact on welfare than the tariff on goods.

Thus, our results may be viewed as a substantial generalization of this proposition to the case of endogenous levels of variety and technology transfer, as determined in a monopolistically competitive equilibrium. Interestingly, in this framework the efficacy of a tariff on technologies as compared to goods is independent of whether a Metzler effects occurs or not, as explained by the discussion at the end of section 3.1: with the number of goods endogenous, the reduction in world variety due to a tariff on goods implies that welfare (real income) rises by less than the tariff revenue, even in the presence of a Metzler effect.

Lastly, what may be inferred from our results concerning national policy the U.S. or other technology exporting countries? First, it would be incorrect to conclude that these countries should impose tariffs on technology transfer, since our welfare results have been derived in a static setting without consideration of tariff retaliation, or more efficient instruments and organizations which could redistribute income internationally. However, it does seems valid to apply our results, for example, when evaluating the desires of groups such as U.S. labor for restrictions on technology transfer. A priori, one may question why these groups should be more concerned with the export of technologies than with the export of raw materials or intermediate products, which presumably could lead to as great an expansion of foreign output, exports, and resulting competition at home. our results point to a special role of technologies as distinct from goods, which is quite consistent with the desires of these special interest groups, and useful in forming a positive interpretation of their lobbying efforts. 
Appendix

The consumer's utility maximization problem is

$$
\max \int_{0}^{v} x(v)^{c} d v \text { subject to } \int_{0}^{v} p(v) x(v) d v=I
$$

where $p(v)$ and $x(v)$ are the price and quantity consumed of good $v, I$ is income, and $\mathrm{V}$ is the total variety (measure) of goods available; for the moment we are not distinguishing between domestic and foreign goods. The elasticity of substitution between goods is given by $\sigma=1 /(1-c)>1$, where $0<c<1$ is assumed.

The first-order conditions for (Al) are

$$
\operatorname{cx}(v)^{c-1}=\lambda p(v), \quad 0 \leq v \leq v \text {, }
$$

where $\lambda$ is the marginal utility of income. It follows that

$$
x(v)=(\lambda p(v) / c)^{-\sigma}
$$

and

$$
\int_{0}^{v} p(v) x(v) d v=(\lambda / c)^{-\sigma} \int_{0}^{v} p(v)^{-d} d v=I \text {, }
$$

where $d=c /(1-c)=\sigma-1>0$. The commodity demand functions are then given by

$$
x(v)=p(v)^{-\sigma} \int_{0}^{v} p(v)^{-d} d v
$$

Thus, the (positive) elasticity of demand for any good equals $\sigma$.

To derive the free trade profit equations (2) and (3), first note that the profit-maximizing prices for goods produced at home and abroad are given by $w / c$ and $w^{*} / c$, respectively, since the elasticity of domestic or world demand is $\sigma=1 /(1-c)$. Substituting these prices into (A2), and noting that $I=w L$ and $I^{*}=w^{\star} I^{*}$, we obtain the quantities consumed 


$$
\begin{aligned}
& x(v)=c L /\left(v+v^{*} \mu^{-d}\right), x\left(v^{*}\right)=\mu^{-\sigma} x(v), \\
& x^{*}(v)=\mu c L^{*} /\left(v+v^{*} \mu^{-d}\right), x^{*}\left(v^{*}\right)=\mu^{-\sigma} x^{*}(v),
\end{aligned}
$$

where $\mu=w^{*} / w, x(v)$ and $x\left(v^{*}\right)$ are the quantitites consumed at home of domestic and foreign goods, and $x^{*}(v)$ and $x^{*}\left(v^{*}\right)$ are the quantitites consumed abroad of imported and local goods. Using (A3) we obtain the free trade profits given in (2) and (3).

For the case of an ad valorem import tariff on goods at rate $t$, with the revenue redistributed to domestic consumers, the quantities consumed (A3) are modified as

$$
\begin{aligned}
& x(v)=c\left(I+t x\left(v^{*}\right) v^{*} / c\right) /\left(v+v^{*}(\mu(1+t))^{-d}\right) \\
& x\left(v^{*}\right)=(\mu(1+t))^{-\sigma} x(v) \\
& x^{*}(v)=\mu c L^{*} /\left(v+v^{*} \sigma^{-d}\right), x^{*}\left(v^{*}\right)=\mu^{-\sigma} x^{*}(v),
\end{aligned}
$$

where $R_{t}=t x\left(V^{*}\right) V^{*} / c$ is the tariff revenue. Substituting (A4) into the profit equations

$$
\begin{aligned}
& \pi=\left(\frac{1}{c}-1\right)\left(x(v)+x^{*}(v)\right)-k \\
& \pi^{*}=\left(\frac{\mu}{c}-\mu\right)\left(x\left(v^{*}\right)+x^{*}\left(v^{*}\right)\right)-k,
\end{aligned}
$$

we obtain expressions for the profits from product development at home and abroad.

For the case of an export tariff on goods at rate $\tau_{x^{\prime}}$ or on technology transfer at rate $\tau_{k^{\prime}}$ (A4) and (A5) must be modified as follows. For the export tariff on goods revenue is $R_{\tau_{x}}=\tau_{x} x^{*}(v) V / c$, while the relative price of imports for home and foreign consumers is $\mu$ and $(1+\tau, x) / \mu$, respectively. For the export 
tariff on technologies revenue is $R_{\tau_{k}}=\tau_{k} k V^{*}$, the relative price of imports for home and foreign consumers is $\mu$ and $1 / \mu$, while the R\&D costs for foreign producers is $k\left(1+\tau_{k}\right)$.

The comparative statics is performed using the equilibrium conditions $\pi=\pi^{\star}=0$ and trade balance. This calculation is simplified by rewriting the trade balance (surplus of the home country) $T$ as follows:

$$
\begin{aligned}
& T=\left(I+\tau_{x}\right) V X^{*}(v) / c+\left(I+\tau_{k}\right) k V^{*}-v^{*} x\left(v^{*}\right) \mu / c \\
& =\left\{\mu L^{*}-V^{*} X^{*}\left(V^{*}\right) \mu / c\right\}+\left(I+\tau_{k}\right) k V^{*}-V^{*} X\left(V^{*}\right) \mu / c
\end{aligned}
$$

using the budget constraint for foreign consumers

$$
\begin{aligned}
& V^{*} x^{*}\left(V^{*}\right) / c+V x^{*}(V)\left(I+\tau_{x}\right) / \mu c=I^{*} \\
& T=-\frac{V^{*} \mu}{c}\left(x\left(V^{*}\right)+x^{*}\left(V^{*}\right)\right)+\left(1+\tau_{k}\right) k V^{*}+\mu L^{*} \\
& =-\frac{V^{*}}{(1-c)}\left(\pi^{*}+k\left(1+\tau_{k}\right)\right)+\left(1+\tau_{k}\right) k V^{*}+\mu L^{*} \\
& \text { since } \\
& \pi^{*}=\left(\frac{\mu}{c}-\mu\right)\left(x\left(V^{*}\right)+x^{*}\left(V^{*}\right)\right)-k\left(1+\tau_{k}\right), \\
& T=-\pi^{*} V^{*} /(1-c)-\left(1+\tau_{k}\right) k V^{*} c /(1-c)+\mu L^{*} .
\end{aligned}
$$

Setting $\pi^{*}=0$ in $(A 6)$, the equilibrium condition $T=0$ can be written as

$$
T=\mu L *-\left(I+\tau_{k}\right) k V^{*} c /(I-c)=0
$$

The comparative statics are performed on the system

$$
\begin{aligned}
\pi & =0 \\
T & =0 \\
\pi-\pi^{*} & =0 .
\end{aligned}
$$


where the second equation refers to (A7). Letting $\tau$ denote any of the three tariffs, or the subsidy on R\&D for domestic use, evaluated at $\tau=0$ we obtain

$$
\left(\begin{array}{l}
d V \\
d V * \\
d \mu
\end{array}\right)=-M^{-1}\left(\begin{array}{l}
\pi_{\tau} \\
T_{\tau} \\
\pi_{\tau}-\pi_{\tau}^{*}
\end{array}\right) d \tau,
$$

where

$$
M^{-1}=\frac{V^{*}}{L^{*}}\left[\begin{array}{ccc}
\frac{-c\left(V+V^{*}\right)}{(1-c)} & 1 & -V^{*}\left(1-\frac{c(2-c)}{(1-c)}\right) \\
0 & -1 & V^{*} \\
0 & 0 & 1
\end{array}\right]
$$

To complete the Appendix we must specify the values of $\pi_{\tau^{\prime}} \pi_{\tau^{\prime}}$, and $T_{T}$ which are substituted into (A8), as follows.

(1) Import tariff on goods: Evaluated at $t=0$,

$$
\pi_{t}=\frac{L V^{*}}{\left(V+V^{*}\right)^{2}}, \quad \pi_{t}^{*}=\frac{-L V}{\left(V+V^{*}\right)^{2}}, \quad T_{t}=0 .
$$

(2) Export tariff on goods: Evaluated at $\tau_{x}=0$, 
31

$$
\pi_{\tau_{x}}=\frac{-L^{*} V^{*}}{\left(V^{*}+V^{*}\right)^{2}}, \quad \pi_{\tau_{x}^{*}}^{*}=\frac{L^{*} V}{\left(V+V^{*}\right)^{2}}, \quad T_{\tau_{x}}=0 .
$$

(3) Export tariff on technologies: Evaluated at $\tau_{k}=0$,

$$
\pi_{\tau_{k}}=\frac{(1-c) k V^{*}}{V+V^{*}}, \quad \pi_{\tau_{k}}^{*}=\frac{(1-c) k V^{*}}{V+V^{*}}-k, \quad T_{\tau_{k}}=\frac{-c k V^{*}}{(1-c)}=-L^{*} .
$$

(4) Subsidy on R\&D for Domestic Use: Evaluated at $s=0$,

$$
\pi_{s}=c k+\frac{(1-c) k V^{*}}{V+V^{*}}, \quad \pi_{s}^{*}=\frac{-(1-c) k V^{*}}{V+V^{*}}, \quad T_{s}=0 .
$$


Footnotes

1 See Dixit and stiglitz (1977, p. 301). They work within a more general framework, where production of a homogeneous numeraire commodity occurs; this good must be omitted to obtain the result stated in the text. The result is also proved in a more general dynamic model by Judd (1980). 2 In writing these utility functions we index goods such that the foreign index $v^{*}$ exceeds the home index $v$. As discussed below, under certain assumptions we shall find that no good is produced in both countries with trade. Note that an asterisk on $v$ refers to the origin of production, while an asterisk on $x$ refers to the origin of demand.

3 An alternative assumption which would imply that no good is produced in both countries is that in addition to the fixed costs of R\&D, there are also fixed country-specific production costs. So long as the country-specific fixed costs are positive and tariffs are infinitesimally small, a firm will never find it profitable to produce a good in both countries, since the additional profits which could be earned by taking advantage of lower wages abroad would be less than the fixed costs of establishing the foreign plant. However, under this alternative assumption the comparative static results reported below would have to be modified slightly, to take account of the domestic and foreign labor engaged in the fixed production cost activity. 4 of course, with large tariffs firms may produce in both countries, and our model thus very naturally extends to an analysis of mutinational firms. The authors are currently engaged in this research, which shall be the topic of another paper.

5 This is a special case of Krugman (1979a).

6 The tariff on technology transfer in regions (B) and (C) is analysed in greater detail in an earlier draft of this paper, Feenstra and Judd (May 1981). 
7 The effects of an export tariff on goods are analysed in greater detail in Feenstra and Judd (May 1981), see also the discussion at the end of this section, and in the Appendix.

8 In section 2 we ruled out the possibility of a firm producing the same good in both countries, but with multi-product firms located in both countries we may still observe internal transfers of knowledge.

9 For the case in which tariff revemues are not redistributed, see Feenstra and Judd (May 1981).

10 For the purpose of this intuitive exercise, we hold $\mathrm{V}$ constant. In fact, holding the terms of trade fixed, the tariff on technologies would tend to increase $v$ due to the redistribution of tariff revenues and the reduction in foreign variety, both of which increase home demand. This rise in $V$ would reinforce our conclusion below that a small tariff on technology transfer, while holding the terms of trade fixed, increases home welfare. 11 This expression may be derived from the demand function (A3), in the Appendix.

12 In this case the govermment would have to use indirect methods to restrict technology transfer, such as a tax on the domestic R\&D activity of foreign firms or foreign profits of home-based firms. These instruments are analysed in the authors" current research on multinationals; see footnote 4. 
$\underline{\text { References }}$

Dixit, A. K. and Norman, V. (1980) Theory of International Trade: A Dual, General Equilibrium Approach (Cambridge University Press: Cambridge, Great Britain).

Dixit, A. and Stiglitz, J. (1977) "Monopolistic Competition and Optimum Product Diversity," American Economic Review 67, June, 297-308.

Feenstra, R. and Judd, K. (1981) "Tariffs, Technology Transfer, and Welfare," University of Chicago, May, mimeo.

Findlay, R. (1978) "Relative Backwardness, Direct Foreign Investment, and the Transfer of Technology: A Simple Dynamic Model," Quarterly Journal of Economics 92, February, 1-16.

Judd, K. (1980) "On the Performance of Patents," University of Chicago, October, mimeo.

Helpman, E. (1980) "International Trade in the Presence of Product Differentiation, Economies of Scale, and Monopolistic Competition: A Chamberlin-Heckscher-Ohlin Approach," forthcoming in the Journal of International Economics.

Krugman, P. (1979a) "Increasing Returns, Monopolistic Competition, and International Trade," Journal of International Economics 9, 469-479. (1979b) "A Model of Innovation, Technology Transfer, and the World Distribution of Income," Journal of Political Economy 87 (2), 253-266.

(1979c) "Scale Economies, Product Differentiation, and the Pattern of Trade," forthcoming in the American Economic Review.

Lancaster, K. J. (1980) "Intra-Industry Trade under Perfect Monopolistic Competition," Journal of International Economics 10 (2), May, 151-175. McCulloch, R. and Yellen, J. L. (1976) "Technology Transfer and the National Advantage," H.I.E.R. Discussion Paper no. 526, Harvard University, December. 
Pugel, T. A. (1980a) "Endogenous Technical Change and International Technology Transfer in a Ricardian Trade Model," International Finance Discussion Paper no. 167, Board of Governors, Federal Reserve, Sept.

Puge1, T. A. (1980b) "Technology Transfer and the Neo-Classical Theory of International Trade," in R. G. Hawkins and A. J. Prasad, eds., Technology Transfer and Economic Development (JAI Press: Greenwich, CT).

Rodriguez, C. A. (1975) "Trade in Technical Knowledge and the National Advantage," Journal of Political Economy 83 (1), February, 121-135.

Vernon, R. (1966) "International Investment and International Trade in the Product Cycle," Quarterly Journal of International Economics 80, May, 190-207. 
CENTRE FOR THE STUDY OF INTERNATIONAL ECONOMIC RELATIONS

RECENT WORKING PAPERS

$\underline{1981}$

8101C Markusen, James R. Factor Movements and Commodity Trade as Compliments: A Survey of Some Cases.

8102C Conlon, R.M. Comparison of Australian and Canadian Manufacturing Industries: Some Empirical Evidence.

$8103 C$

$8104 \mathrm{C}$

Conlon, R.M. The Incidence of Transport Cost and Tariff Protection: Some Australian Evidence.

$8105 \mathrm{C}$

Laidler, David. On the Case for Gradualism.

Wirick, Ronald G. Rational Expectations and Rational Stabilization Policy in an Open Economy.

$8106 \mathrm{C}$

Mansur, Ahsan and John Whalley Numerical Specification of Applied General Equilibrium Models: Estimation, Calibration, and Data.

$8107 \mathrm{C}$

Burgess, David F., Energy Prices, Capital Formation, and Potential GNP

$8108 C$ DSU

Jimenez, E. and Douglas H. Keare. Housing Consumption and Income in the Low Income Urban Setting: Estimates from Panel Data in El Salvador

8109C DSU Whalley, John Labour Migration and the North-South Debate

8110C Manning, Richard and John McMillan Government Expenditure and Comparative Advantage

$8111 \mathrm{C}$

Fried, Joel and Peter Howitt Why Inflation Reduces Real Interest Rates

1982

8201C Manning, Richard and James R. Markusen Dynamic Non-Substitution and Long-Run Production Possibilities

$8202 \mathrm{C}$

Feenstra, Robert and Ken Judd Tariffs, Technology Transfer, and Welfare 